\title{
Coagulantes Naturais Utilizados no Tratamento de Efluentes em Indústrias Têxteis
}

\author{
Natural Coagulants Used in Effluent Treatment in Textile Industries
}

\author{
Jéssica Gabryelle dos Santos Silva ${ }^{1}$ \\ Renato Souza Mendes Junior ${ }^{1}$ \\ Ana Katerine de Carvalho Lima Lobato ${ }^{1}$ \\ Universidade Salvador, Salvador, BA, Brasil
}

\begin{abstract}
Resumo
Coagulantes inorgânicos e sintéticos são os mais utilizados no tratamento de efluentes em indústrias têxteis, no entanto, seu uso já vem sendo questionado pelo fato de elevar o custo do processo, além dessa prática despejar metais pesados residuais no efluente, prejudicando a saúde humana e animal. Como solução, uma alternativa sustentável é o uso de coagulantes naturais no processo. Para tanto, este estudo produziu uma prospecção tecnológica de coagulantes naturais no tratamento de efluentes em indústrias têxteis, mapeando os resultados relacionados ao seu uso. Uma busca avançada foi realizada utilizando as palavras-chave treatment, effluent, coagulant, natural e textile. A pesquisa resultou apenas em uma patente publicada em 2017 e em dez artigos publicados no intervalo de 2014 a 2019. Com base na avaliação do material publicado, pode-se concluir que as sementes de Moringa oleífera são as mais utilizadas para o tratamento, atuando sozinhas como agentes de coagulação com elevada eficiência, principalmente na remoção da cor e da turbidez.
\end{abstract}

Palavras-chave: Rejeito. Tóxico. Orgânico.

\begin{abstract}
In the treatment of effluents in the textile industries, inorganic and synthetic coagulants are the most used, however, their use has been questioned due to costs, in addition to dumping residual metals into the effluent, harming human and animal health. In solution, an alternative is the use of natural coagulants in the process. This study carried out a technological prospecting of natural coagulants in the treatment of textile effluents, mapping the results related to their use. An advanced search was performed using the keywords treatment, effluent, coagulant, natural and textile. The research resulted only in a patent published in 2017 and ten articles published in the period from 2014 to 2019. Based on the evaluation of the published material, it can be concluded that, Moringa oleifera seeds are the most used for the treatment, acting alone as coagulation agents, with high efficiency, mainly in the removal of color and turbidity.
\end{abstract}

Keywords: Waste. Toxic. Organic.

Área Tecnológica: Tratamento de Efluentes. Engenharia Química. 


\section{Introdução}

Nas últimas décadas, com o crescimento populacional e o aumento da atividade industrial, a contaminação das águas naturais se tornou mais expressiva. Os processos industriais são os que mais consomem água. No caso da indústria têxtil, por exemplo, as operações de limpeza, tingimento e acabamento consomem grandes volumes de água, revelando a necessidade de existir um controle e um tratamento mais intensivo desses despejos (SCHOENHALS; PORTO, 2012).

Os resíduos têxteis são fortemente coloridos, eles possuem elevado peso molecular e baixa biodegradabilidade, se descartados de forma incorreta, podem prejudicar a sobrevivência da fauna e da flora. Tendo em vista esses problemas ambientais, o Conselho Nacional do Meio Ambiente (CONAMA), por meio da Resolução n. 430, de 13 de maio de 2011, descreve as condições-padrão para o lançamento de efluentes em corpos hídricos. Segundo a Resolução, o despejo desses resíduos deve ser previamente tratado conforme prevê o regulamento disposto na resolução ou em normas aplicáveis, não podendo causar contaminação das águas superficiais ou subterrâneas (BRASIL, 2011). A Tabela 1 descreve os parâmetros estabelecidos pelo artigo 16 da RDC n. 430/2011.

Tabela 1 - Parâmetros estabelecidos pela RDC n. 430/2011 do CONAMA

\begin{tabular}{ccc} 
CaRActerística & VAlOR ESPECIFICADO & UnidADE \\
pH & 5 a 9 & - \\
DBO & 60 & $\%$ \\
Sólidos sedimentáveis & máx. 1,0 & $\mathrm{~mL} / \mathrm{L}$ \\
Temperatura & máx. 40 & ${ }^{\circ} \mathrm{C}$ \\
Vazão & $1,5 \times \mathrm{Q}^{*}$ & - \\
Óleos minerais & máx. 20 & $\mathrm{mg} / \mathrm{L}$ \\
Óleos vegetais e gordura animal & máx. 50 & $\mathrm{mg} / \mathrm{L}$ \\
Materiais flutuantes & Ausência & - \\
\hline
\end{tabular}

Nota: * $\mathrm{Q}$ = Vazão média do período diário; $\mathrm{DBO}$ - Demanda Bioquímica de Oxigênio em 5 dias a $20^{\circ} \mathrm{C}$.

Fonte: Adaptada de Brasil (2011)

A Resolução n. 430/2011 não deixa especificado os valores-limite para despejo acerca da Demanda Química de Oxigênio (DQO). Alguns estados brasileiros apresentam leis estaduais que padronizam os parâmetros para liberação dos efluentes, como os estados de Pernambuco (PE) e Rio Grande do Sul (RS), que possuem parâmetros de DQO baseados na quantidade de efluentes e, entre estes, apenas o RS faz referência à vazão diária (MORAIS; SANTOS, 2019). A Tabela 2 retrata os parâmetros para padrões de emissão de efluentes líquidos, presente na Resolução n. 128/2006 do Conselho Estadual do Meio Ambiente (CONSEMA), disponibilizado pela Secretaria de Meio Ambiente do Estado do Rio Grande do Sul. 
Tabela 2 - Concentração padrão de DQO por emissão de efluentes

$\begin{array}{cc}\text { DQO (MG O/L) } & \text { VAZÃo (Q) }\left(\mathbf{M}^{\mathbf{3}} / \mathbf{D I A}\right) \\ 20 \leq 20 & 400 \\ 100 \leq \mathrm{Q} \leq 100 & 360 \\ 500 \leq \mathrm{Q} \leq 1000 & 330 \\ 1000 \leq \mathrm{Q} \leq 3000 & 300 \\ 3000 \leq \mathrm{Q}<7000 & 260 \\ 7000 \leq \mathrm{Q}<10^{4} & 200 \\ \mathrm{Q} \leq 10^{4} & 180\end{array}$

Fonte: Adaptada de Rio Grande do Sul (2006)

\subsection{Coagulantes}

Frequentemente, os efluentes desse processo são tratados por meio de processo físico-químico, sendo composto de: coagulação, floculação e sedimentação. Segundo Martins (2014), a coagulação e a floculação são processos que reduzem a turbidez e ajudam na deposição de partículas, enquanto, na floculação, ocorre a clarificação por atividade física. Os coagulantes possuem papel importante, pois neutralizam e aglomeram os coloides (partículas suspensas), facilitando a separação na próxima etapa. Usualmente, os coagulantes utilizados são inorgânicos e/ou sintéticos, compostos em sua maioria por alumínio. Ao final do processo, acabam liberando concentrações residuais de metais que foram utilizados no tratamento, aumentando a carga poluente ao lodo gerado, como também elevando os riscos à saúde, pois a exposição ao alumínio, por exemplo, pode desencadear doenças neurodegenerativas, como Parkinson $e$ Alzheimer (LIMA JÚNIOR; ABREU, 2018).

A comunidade ambientalista incentiva que pesquisadores busquem alternativas sustentáveis e rentáveis para o tratamento de efluentes (FERNANDES et al., 2019). Tendo em conta os problemas ambientais, é muito promissor o uso de coagulantes naturais no processo de tratamento de efluentes, principalmente por se tratar de produtos com elevada disponibilidade e biodegradabilidade, podendo, inclusive, reduzir o custo final do processo (LIMA JÚNIOR; ABREU, 2018).

Atualmente, alguns coagulantes naturais são comercializados na forma de taninos, que são comumente extraídos de vegetais, por exemplo, da casca ou madeira Acácia Negra, Castanea schinopsis. Taninos, também conhecidos como polímeros de Mannich, são coagulantes naturais de natureza poli-iônica (SALEEM; BACHMANN, 2019). Na Tabela 3, é possível visualizar os exemplos comerciais utilizados no tratamento de águas residuais. 
Tabela 3 - Taninos comerciais utilizados como coagulantes

\begin{tabular}{|c|c|c|c|}
\hline TANino Comercial & EMPRESA & ORIGEM Vegetal & Uso \\
\hline TANFLOC & $\begin{array}{l}\text { TANAC } \\
\text { (Brasil) }\end{array}$ & Acacia mearnsii & $\begin{array}{l}\text { Pode atuar sozinho como agente coagulante ou } \\
\text { em combinação com outro agente inorgânico }\end{array}$ \\
\hline ACQUAPOL & SETA (Brasil) & Acacia mearnsii & Agente coagulante \\
\hline SILVAFLOC & $\begin{array}{l}\text { SILVATEAM } \\
\text { (Itália) }\end{array}$ & Schinopsis balansae & $\begin{array}{l}\text { Pode atuar sozinho como agente coagulante ou } \\
\text { em combinação com outro agente inorgânico }\end{array}$ \\
\hline KLARAID 6400 & $\begin{array}{l}\text { DEARBORN } \\
\text { Chemical } \\
\text { (EUA) }\end{array}$ & Extrato de Mimosa & $\begin{array}{l}\text { Pode atuar sozinho como agente } \\
\text { coagulante ou em combinação } \\
\text { com outro agente inorgânico }\end{array}$ \\
\hline
\end{tabular}

Fonte: Adaptada de Saleem e Bachmann (2019)

Diante disso, por meio deste trabalho, pretende-se analisar os estudos desenvolvidos que comprovam a eficiência de produtos naturais como agentes coagulantes no tratamento de efluentes oriundos de indústrias têxteis. A análise, realizada por meio da prospecção tecnológica, permitirá discutir sobre o processo relacionando ao seu impacto ambiental, caracterizar os efluentes têxteis e apontar os parâmetros de qualidade, conforme prevê a legislação brasileira. Ao final, será possível identificar quais os produtos naturais que podem ser utilizados como coagulantes naturais, relatando a eficiência no tratamento desse tipo de efluente com o intuito de auxiliar na criação de novas tecnologias pertinentes ao tema.

\section{Metodologia}

Foi feita uma prospecção tecnológica entre os meses de agosto e setembro de 2019 a partir da análise de artigos científicos nacionais e internacionais, assim como em análises de patentes.

As buscas de artigos científicos foram realizadas em sites e em revistas especializadas, como Science Direct, Scopus, Scielo e Portal Capes, usando a pesquisa avançada. Foram considerados os artigos publicados entre 2009 e 2019, utilizando-se as palavras-chave: treatment, effluent, coagulant, natural e textile, contidas nos títulos dos artigos, no resumo e/ou nas palavras-chave. O levantamento bibliográfico também considerou os repositórios de Universidades renomadas brasileiras para melhor entendimento acerca do assunto.

A busca de patente foi realizada no Espacenet, base de dados gratuita do Escritório Europeu de Patentes (EPO), e no Instituto Nacional da Propriedade Industrial (INPI). A pesquisa avançada utilizou operadores booleanos ("AND" e "OR") e de proximidade (")"), considerando como palavras-chave: treatment, effluent, coagulant e textile, contidas no intervalo de tempo entre 2009 a 2019. Os resultados obtidos foram analisados e tratados de acordo com os parâmetros estabelecidos pela legislação brasileira.

\section{Resultados e Discussão}

Os resultados obtidos no mapeamento foram divididos em prospecção tecnológica das patentes e avaliação dos estudos científicos em websites, de acordo com os estudos desenvolvidos entre os anos de 2009 a 2019. Com base nos tópicos, foram avaliados a influência do tipo de 
coagulante utilizado e os resultados obtidos de acordo com a legislação para adequação do efluente ao seu descarte final.

\subsection{Prospecção Tecnológica das Patentes}

O resultado da pesquisa avançada resultou em quatro patentes depositadas no banco Espacenet, utilizando-se as palavras-chave treatment, effluent, coagulant e textile. Os trabalhos encontrados foram analisados para avaliar se discutiam sobre o tratamento de efluentes têxteis utilizando coagulantes naturais. No caso do INPI, não foi encontrado nenhuma patente relacionada ao tema, utilizando-se todas as palavras-chave no intervalo de tempo estabelecido.

Foi analisado o conteúdo descritivo das quatro patentes e, assim, apenas uma delas se encaixava com a temática da pesquisa. A China é a detentora dessa patente registrada no ano de 2017. Esse país é o maior fabricante mundial da indústria têxtil e de vestuário, por isso, justifica-se ele ter um interesse tecnológico/sustentável nessa área. Por ser um estudo novo, revela-se a importância ambiental sobre o tema em que muitas tecnologias e pesquisas desenvolvidas são recentes, talvez, por isso, podendo, tais tecnologias não tenham sido patenteadas ou desenvolvidas. Essa pesquisa comprova a necessidade de impulsionar e de financiar esses projetos, já que esses projetos sugerem alternativas sustentáveis que minimizam grandes impactos ambientais.

Três das quatro patentes encontradas foram rejeitadas por focarem na construção do sistema de tratamento de águas residuais têxteis e não na utilização de coagulantes naturais para tratamento do efluente. Já a patente analisada descreve um processo de tratamento do tingimento e de acabamento de águas residuais em um moinho de lã. O sistema compreende filtrar o lodo gerado nas etapas citadas, adicionar uma solução ácida para regular o $\mathrm{pH}$ alcalino, utilizando coagulantes microbianos. As águas são clarificadas e desinfetadas com ação oxidativa de ozônio, um processo de baixo custo operacional, alta eficiência e menor intensidade de trabalho [CN106746164 (A)].

\subsection{Avaliações dos Estudos Científicos de Websites}

Os resultados encontrados demostram bastante interesse em alternativas sustentáveis para o tratamento de efluentes, principalmente na indústria têxtil devido à toxicidade do efluente liberado no processo. A Tabela 4 apresenta os resultados encontrados, considerando cada palavra-chave na pesquisa. Com isso, pode-se concluir que a temática sobre o tratamento de efluentes é bastante difundida, no entanto, quando a pesquisa se torna mais restrita, esse número se reduz, tendo ao final apenas 20 estudos utilizando as cinco palavras-chave.

Tabela 4 - Resultados obtidos na busca de artigos científicos nos bancos de websites

\begin{tabular}{|c|c|c|c|c|c|}
\hline TREATMENT & EFFLUENT & COAGULANT & NATURAL & TeXtILE & Resultado \\
\hline$X$ & & & & & 5.642 .670 \\
\hline$X$ & $X$ & & & & 45.084 \\
\hline $\mathrm{X}$ & $\mathrm{X}$ & $\mathrm{X}$ & & & 752 \\
\hline $\mathrm{X}$ & $\mathrm{X}$ & $\mathrm{X}$ & $\mathrm{X}$ & & 132 \\
\hline $\mathrm{X}$ & $\mathrm{X}$ & $\mathrm{X}$ & $\mathrm{X}$ & $\mathrm{X}$ & 20 \\
\hline
\end{tabular}

Fonte: Elaborada pelos autores deste artigo (2019) 
A Figura 1 mostra a distribuição dos artigos publicados, tanto por país de publicação (A) quanto pelo ano de publicação (B). No entanto, quatro artigos encontrados eram iguais, passando-se a considerar apenas um deles, e outros sete artigos, apesar de conter as palavras-chaves, ao analisar o conteúdo do resumo por completo, verificou-se que não contemplava a temática da pesquisa. Tendo em vista esses parâmetros, ao final da análise, dos 20 artigos encontrados, considerou-se apenas 10.

Figura 1 - Distribuição da quantidade de artigos publicados por país (A) e pelo ano de publicação (B)

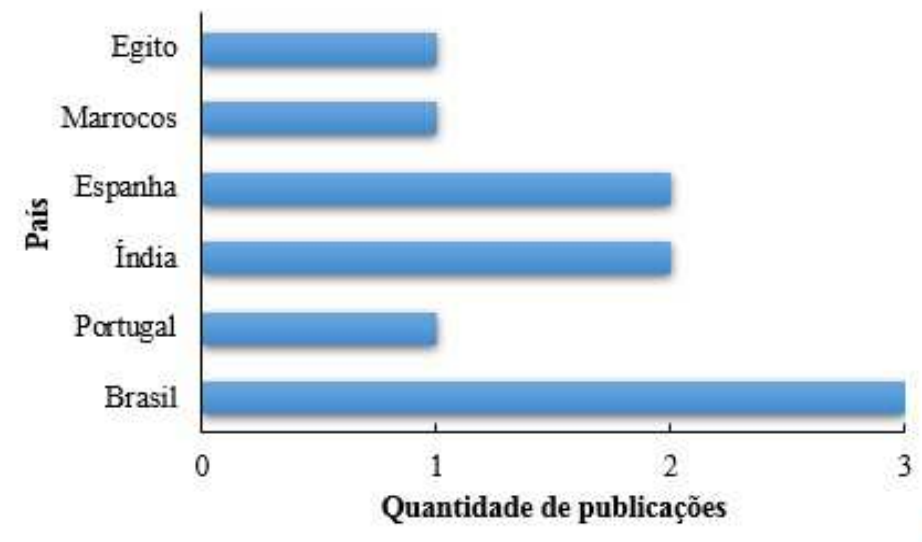

(A)

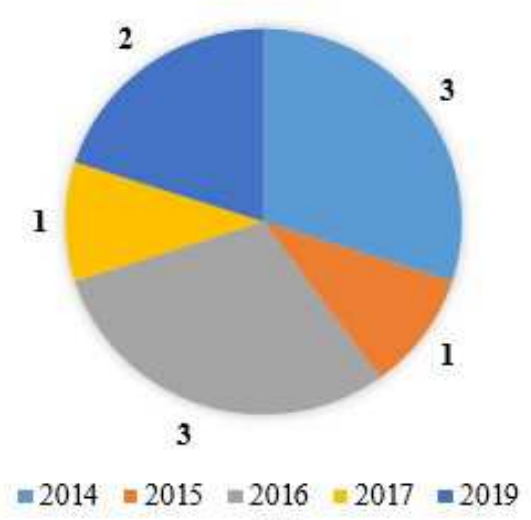

(B)

Fonte: Elaborada pelos autores deste artigo (2019)

Diferente da busca de patentes, a pesquisa em websites revelou outros países que estão dominando as pesquisas no intervalo de tempo estabelecido. O Brasil lidera o ranking, e o interesse brasileiro nesse ramo de pesquisa pode ser justificado pela sua biodiversidade na fauna e na flora, uma vez que, segundo Saleem e Bachmann (2019), muitos coagulantes são originados de plantas oriundas de países com climas tropicais e equatoriais. É importante para todos os países envolvidos incentivarem pesquisas que promovam soluções contidas dentro da sua própria realidade.

Como mostra a Figura 2 (B), observa-se que, entre 2009 a 2013, nenhuma pesquisa foi encontrada nessa área. A motivação para os estudos começou a ser impusionada a partir de 2014, tendo sua quantidade máxima de publicações em 2014 e 2016 . Houve uma pausa em 2018, sem nenhuma publicação, incentivos a esse tipo de estudo podem gerar mais publicações nos próximos anos e muitas pesquisas podem estar sendo desenvolvidas.

\subsection{Avaliação dos Coagulantes Utilizados}

A Tabela 5 foi elaborada com os resultados encontrados e avaliados para cada organismo utilizado. Em seguida, foram relatados as eficiências e os resultados encontrados em cada estudo. 
Tabela 5 - Resultados obtidos em percentual de redução final alcançada nos estudos encontrados utilizando os coagulantes naturais

\begin{tabular}{|c|c|c|c|c|c|c|c|c|c|c|}
\hline REFERÊNCIA & $\begin{array}{l}\text { COAgulante } \\
\text { NATURAL }\end{array}$ & Funçẫo & Origem/Parte & $\mathbf{T}\left({ }^{\circ} \mathbf{C}\right)$ & $\begin{array}{c}\text { REDUÇÃO DE } \\
\text { DQO (\%) }\end{array}$ & $\begin{array}{l}\text { REDUÇÃO DE } \\
\text { DBO }_{5}(\%)\end{array}$ & $\begin{array}{c}\text { REDUÇÃO DE } \\
\text { TUR (\%) }\end{array}$ & $\begin{array}{c}\text { EREUÇão DE } \\
\text { TSS (\%) }\end{array}$ & $\begin{array}{c}\text { PH } \\
\text { FINAL }\end{array}$ & $\begin{array}{c}\text { REduÇão } \\
\text { DA CoR } \\
(\%)\end{array}$ \\
\hline $\begin{array}{c}\text { Muralimohan } \\
\text { e } \\
\text { Palanisamy } \\
\text { (2014) }\end{array}$ & $\begin{array}{c}\text { Moringa } \\
\text { oleífera }^{1} \\
\text { Tamarina indica }^{2} \\
\text { Potatorum } \\
\text { Strychonomous }\end{array}$ & $\begin{array}{l}\text { Diferentes } \\
\text { funções* }\end{array}$ & Sementes & N.A & 79,34 & 72,29 & 82,10 & 80,56 & 6 & N.A \\
\hline $\begin{array}{l}\text { Vilaseca et } \\
\text { al. (2014) }\end{array}$ & Moringa oleífera & $\begin{array}{l}\text { Agente de } \\
\text { coagulação }\end{array}$ & Sementes & N.A & N.A & N.A & N.A & N.A & 9 & $80-95$ \\
\hline $\begin{array}{l}\text { Freitas et } \\
\text { al. }(2015)\end{array}$ & $\begin{array}{l}\text { Abelmoschus } \\
\text { esculentus }\end{array}$ & $\begin{array}{l}\text { Auxiliar de } \\
\text { coagulação }\end{array}$ & Mucilagem & N.A & 85,69 & N.A & 97,24 & N.A & 6 & 93,57 \\
\hline $\begin{array}{l}\text { Pavankumar } \\
\text { e Singh } \\
\text { (2015) }\end{array}$ & Moringa oleífera & $\begin{array}{l}\text { Agente de } \\
\text { coagulação }\end{array}$ & Sementes & N.A & N.A & N.A & N.A & N.A & N.A & 58,3 \\
\hline $\begin{array}{l}\text { Ali e El- } \\
\text { Mohamedy } \\
(2016)\end{array}$ & Moringa oleífera & $\begin{array}{l}\text { Agente de } \\
\text { coagulação }\end{array}$ & Sementes & N.A & N.A & N.A & N.A & N.A & 8 & 90 \\
\hline $\begin{array}{l}\text { Lozano- } \\
\text { Rivas et } \\
\text { al. (2016) }\end{array}$ & Furcraea sp. & $\begin{array}{l}\text { Auxiliar de } \\
\text { coagulação }\end{array}$ & Folhas & 17,6 & N.A & N.A & 93 & N.A & 7 & 89 \\
\hline $\begin{array}{c}\text { Souza et } \\
\text { al. }(2016)\end{array}$ & $\begin{array}{c}\text { Cereus } \\
\text { peruvianus }\end{array}$ & $\begin{array}{l}\text { Auxiliar de } \\
\text { coagulação }\end{array}$ & Mucilagem & N.A & 58,3 & N.A & 85,40 & N.A & 5 & N.A \\
\hline $\begin{array}{l}\text { Bouaouine } \\
\text { et al. (2017) }\end{array}$ & Moroccan cactus & $\begin{array}{l}\text { Auxiliar na } \\
\text { coagulação }\end{array}$ & Mucilagem & N.A & N.A & N.A & 96 & N.A & 10 & N.A \\
\hline $\begin{array}{l}\text { Santos et } \\
\text { al. }(2019)\end{array}$ & Moringa oleífera & $\begin{array}{l}\text { Agente de } \\
\text { coagulação }\end{array}$ & Sementes & 20 & 79,7 & 88,90 & 76,2 & 85,5 & 5,5 & 93 \\
\hline $\begin{array}{l}\text { Lopes et } \\
\text { al. (2019) }\end{array}$ & TANFLOC SG & $\begin{array}{l}\text { Agente de } \\
\text { coagulação }\end{array}$ & Acacia mearnsii & N.A & N.A & N.A & N.A & N.A & 8 & 100 \\
\hline
\end{tabular}

Nota 1: N.A = Não Avaliado; TSS = Sólidos totais sedimentáveis; $\mathrm{T}=$ Temperatura; TUR = Turbidez.

Nota 2: * Os coagulantes apresentam diferentes funções, atuando como: ${ }^{1}$ Agente de coagulação $e^{2,3}$ Auxiliares de coagulação.

Fonte: Elaborada pelos autores deste artigo (2019)

\subsubsection{Moringa oleífera}

É possível observar a aplicação e a origem de cada material da Moringa oleífera, na análise, observou-se que todos os artigos encontrados optaram pela utilização de plantas para a comparação da eficiência no tratamento de efluentes têxteis, apesar de a literatura mostrar outras opções, como rotíferos, microcrustáceos e bactérias.

Com exceção da Moringa oleífera e do tanino comercial Tanfloc SG, os demais organismos sozinhos não podem atuar como agentes coagulantes no processo. Dessa forma, eles são combinados com coagulantes inorgânicos, reduzindo as quantidades utilizadas e diminuindo o custo e a massa do lodo final gerado, sem afetar na efetividade do processo. A falta de caracterização do efluente bruto pelos autores, com exceção da pesquisa de Muralimohan e Palaninsamy (2014), inviabilizou mensurar a efetividade do tratamento para a maioria dos parâmetros. Assim, os resultados foram expressos em porcentagem (\%). Excepcionalmente, o valor final da Demanda Bioquímica de Oxigênio (DBO), em cinco dias a $20^{\circ} \mathrm{C}$, é representado em termos de porcentagem de redução em relação ao valor inicial, antes do tratamento com o coagulante. 
As sementes de Moringa oleífera são mais indicadas para $\mathrm{pH}$ alcalino, característica mais difundida na literatura para efluente têxtil, sendo bastante eficaz para o tratamento desse efluente. Essa comprovação foi observada nos estudos de Vilaseca, López-Grimau e Gutiérrez-Bouzán (2014). Para coagulantes que atuam melhor em pH ácido, necessita-se uma correção prévia do pH para maior eficiência. O uso de Moringa oleífera apresentou neste estudo um rendimento para remoção de cinco principais corantes reativos da família de azocorantes em efluentes têxteis, alcançando até $95 \%$ de remoção de cor. Ao fim, o estudo reforça que a água tratada ainda pode ser reutilizada em novos processos de tingimento, minimizando desperdícios.

Já Pavankum e Singh (2015) e Ali e El-Mohamedy (2016) tiveram como abordagem principal o uso do coagulante apenas para remoção da cor. Moringa oleífera, no estudo de Ali e El-Mohamedy (2016), alcançou 90\% de remoção de corante em meio acalino (pH 8,0). Entretanto, os demais parâmetros especificados pela legislaçao não foram estudados, inviabilizando concluir a eficácia desse coagulante no tratamento total do efluente por meio desses dois estudos.

Para águas residuais com elevada DQO, observa-se, por meio desses resultados, que Moringa oleífera seria o coagulante mais indicado, sendo mais efetivo no processo. Para DBO, o melhor resultado foi o de Santos et al. (2019), com uma diminuição de 88,9\%. Essa pesquisa, também, foi a mais completa, apresentando avaliação de todos os parâmetros como pode ser observado na Tabela 5. Todos os trabalhos que avaliaram a DBO estavam dentro dos parâmetros do Conama, que determina que a quantidade mínima seja de $60 \%$ de redução em relação ao valor inicial de DBO.

\subsubsection{Furcraea sp.}

Outro coagulante natural foi extraído das folhas da Furcraea sp., planta característica de clima tropical, sendo encontrada principalmente na América Central e do Sul, em países como o Brasil. O estudo de Lozano-Rivas et al. (2016) utilizou esse organismo como auxiliar de coagulação, combinado com doses variadas de cloreto férrico hexahidratado $\left(\mathrm{FeCl} \cdot 6 \mathrm{H}_{2} \mathrm{O}\right)$, utilizado no tratamento de águas residuais. O resultado proporcionou a redução de $89 \%$ da cor do efluente, usando apenas $20 \mathrm{mg} / \mathrm{L}$ de coagulante natural. Essa combinação resultou em uma remoção adicional de $31 \%$ de cor e $17 \%$ de turbidez, em relação aos resultados obtidos com o coagulante inorgânico utilizado isoladamente. Ao final, o uso da Furcraea sp contribuiu também para redução de custo do uso de cloreto férrico hexahidratado, além de menor eliminação de metais pesados, como o ferro, no efluente final tratado.

\subsubsection{Abelmoschus esculentus}

A atividade do coagulante natural Abelmoschus esculentus foi investigada por Freitas et al. (2015) e sua atuação foi combinada com o cloreto férrico (agente químico). O maior valor relatado por esse estudo foi utilizando uma dosagem de 3,20 mg/L de Abelmoschus esculentus mais $88,0 \mathrm{mg} / \mathrm{L}$ de $\mathrm{Fe}^{3+}$, reduzindo $72,5 \%$ da quantidade de agente inorgânico utilizado, o que provoca a redução dos níveis de metal despejado no lodo final. Os autores, ainda, salientaram em seu estudo que o coagulante utilizado possui maior eficiência em $\mathrm{pH}$ ácido e que o efluente têxtil é tipicamente básico, necessitando haver uma correção desse valor. 
Os autores comprovaram a eficiência na remoção da turbidez, da cor e da DQO, alcançando 97,24\%, 93,57\% e 85,69\% de redução, respectivamente, para cada parâmetro. Assim, as pesquisas realizadas por Freitas et al. (2015) e por Bouaouine et al. (2017) alcançaram os maiores valores de redução de turbidez, com diferentes coagulantes. A redução da turbidez é importante para as etapas conseguintes, porque quanto menor a turbidez, mais fácil será a floculação, aumentando também a eficiência da sedimentação desses flóculos no processo $e$ dando efetividade do tratamento.

\subsubsection{Cereus peruvianus}

A ação coagulante do produto da mucilagem do cacto Cereus peruvianus foi investigada por Souza et al. (2016). O componenete ativo do cacto foi obtido por meio da extração salina. A estabilidade do organismo foi avaliada, mantendo suas características por quatro dias de armazenamento em temperatura ambiente. O organismo atuou como auxiliar de coagulação, pois foi associado em diferentes dosagens com cloreto férrico $(\mathrm{FeCl})$. Não foi tão eficaz na remoção de DQO como os outros já citados, alcançando cerca de 58,3\% de remoção desse parâmetro. Entretanto, quanto à turbidez, foi alcançado $85,40 \%$ de remoção.

\subsubsection{Moroccan cactus}

Bouaouine et al. (2017) compararam a ação de dois coagulantes inorgânicos em relação a um coagulante natural obtido da mucilagem de Moroccan cactus. Os autores concluíram que para uma remoção de 97 a $98 \%$ de turbidez, o cloreto férrico $(\mathrm{FeCl})$ e o sulfato de alumínio (AlSO) geraram $380 \mathrm{~mL} / \mathrm{L}$ e $360 \mathrm{~mL} / \mathrm{L}$ de lama, respectivamente, enquanto o coagulante natural acrescentou apenas $3,3 \mathrm{~mL} / \mathrm{L}$ de lama ao lodo gerado. Assim, esse estudo foi eficiente, principalmente, na identificação da redução do volume final de efluente tratado.

\subsubsection{Tanfloc SG}

Para este produto já há opções comerciais, como no estudo de Lopes et al. (2019) que utilizou um tanino comercial extraído da casca da Acacia mearnsii. Os autores observaram que o tanino foi capaz de remover $100 \%$ de cor. Utilizou-se um coagulante comercial, conhecido como Tanfloc SG. Seu nome se deve ao fato de ser composto de taninos, substâncias naturais que são encontradas principalmente nos caules, folhas e sementes de plantas, como no caso da Acacia mearnsii. O estudo objetivou utilizar o coagulante disponibilizado pelo mercado para avaliação da remoção de corantes “azo”, conhecidos pelo seu caráter cancerígeno e mutagênico. Os autores estudaram os efeitos de $\mathrm{pH}$ das dosagens do coagulante comparando aos sintéticos/ inorgânicos. Ao final, comprovou a remoção de $100 \%$ da cor com $180 \mathrm{mg} / \mathrm{L}$ de coagulante tanino, enquanto $240 \mathrm{mg} / \mathrm{L}$ de sulfato férrico não foram suficientes para alcançar mais que $20 \%$ de descoloração, gerando um lodo maior que o primeiro com coagulante natural. 


\section{Considerações Finais}

Com prospecção tecnológica, concluiu-se que a temática sobre coagulantes naturais utilizados para o tratamento de efluentes têxteis é recente, os trabalhos foram encontrados no intervalo de 2014 a 2019. Apenas uma patente foi encontrada, ela foi publicada em 2017 de autoria chinesa. Já nos artigos científicos, o Brasil foi o líder com três publicações sobre o assunto. No geral, os estudos não trazem todos os parâmetros que devem ser avaliados para o tratamento do efluente de acordo com a legislação brasileira, no entanto, esses estudos comprovam a eficiência na remoção da cor e turbidez.

O tema vem sendo desenvolvido principalmente por países equatoriais, tropicais e de clima temperado. $\mathrm{O}$ que pode ser justificado pela disponibilidade de organismos para aplicação nesses estudos, como as plantas, os principais precursores dos organismos utilizados nas pesquisas. O uso dos coagulantes também comprovou a redução do lodo gerado no processo, uma vez que a grande preocupação é a liberação dos metais pesados no descarte final ao utilizar os coagulantes inorgânicos. Existem várias formas de extração desses materiais, mas a mucilagem foi a mais difundida. Analisou-se também que as sementes de Moringa oleífera são as mais procuradas para o tratamento. Essa planta e o tanino comercial Tanfloc SG foram os únicos utilizados como agentes coagulantes, sem necessitar que haja a combinação com outro organismo para efetividade do processo de tratamento.

Desse modo, os coagulantes naturais podem substituir os sintéticos/inorgânicos para atuarem na remoção de cor e de turbidez dos efluentes têxteis industriais. Sua eficiência foi comprovada nos estudos apresentados para esses dois parâmetros, no entanto, para que seja ampliada a eficácia do tratamento a nível da legislação vigente, é necessário que todas as variáveis sejam estudadas a fundo. Foi observada, também, a simulação de situações reais a nível laboratorial, de forma que é interessante que situações reais sejam realmente avaliadas e não simuladas, por exemplo, em áreas experimentais ou até em estações de tratamento de efluentes. No mais, este trabalho pode servir como base inicial para que a iniciativa privada, por meio das próprias empresas do ramo, patrocine e atue em parceria com pesquisadores que aperfeiçoem e desenvolvam alternativas sustentáveis para esse tratamento. Assim, se terá um beneficiamento em toda a comunidade, uma vez que essa prática estará incentivando a sustentabilidade, a biodegradabilidade e a redução de custos no processo.

\section{Referências}

AKPOMIE, K. G. et al. Coagulation-Flocculation process of Citropsis articulata seed powders as natural coagulant for textile effluent. Leonardo Electronic Journal of Practices and Technologies, [S.l.], n. 32, p. 271-284, 2018.

ALI, N.; HAMEED, A.; AHMED, S. Physicochemical characterization and bioremediation perspective of textile effluent, dyes and metals by indigenous bacteria. Journal of Hazardous Materials, [S.l.], v. 164, n. 1, p. 322-328, 2009.

ALI, N. F; EL-MOHAMEDY, R. S. R. Evaluation of Moringa oleifera seed extract coagulation in removal of some dyes in textile wastewater. International Journal of ChemTech Research, [S.I.], v. 9, p. 538-545, 2016. 
ALMEIDA, E. J. R.; CORSO, C. R. Comparative study of toxicity of azo dye Procion Red MX-5B following biosorption and bodegradation treatments with the fungi Aspergillus niger and Aspergillus terreus. Chemosphere, [S.I.], v. 112, p. 317-322, 2014.

ALVES, P. A. Tratamento eletroquímico e eletroquímico foto-assistido na degradação de efluentes da indústria têxtil. 2010. 103 p. Tese (Doutorado) - Instituto de Química de São Carlos, Universidade de São Paulo, São Carlos, 2010.

ANASTASI, A. et al. Decolourisation and detoxification in the fungal treatment of textile wastewaters from dyeing processes. New Biotechnology, [S.1.], v. 29, n. 1, p. 39-45, 2011.

ANASTASAKIS, K.; KALDERIS, D.; DIAMADOPOULOS, E. Flocculation behavior of mallow and okra mucilage in treating wastewater. Desalination, [S.1.], v. 249, n. 2, p. 786-791, 2009.

BAÊTA, B. E. L. Tratamento de Efluentes de Indústria Têxtil Utilizando Reatores Anaeróbios de Membranas Submersas (SAMBR) com e sem Carvão Ativado em Pó (CAP). 2012. 107 p. Dissertação (Mestrado) - Curso de Engenharia Ambiental, Programa de Pós-Graduação em Engenharia Ambiental, Universidade Federal de Ouro Preto, Ouro Preto, 2012.

BELTRAME, L. T. C. Caracterização de efluente têxtil e proposta de tratamento. 2000. 179 f. Dissertação (Mestrado) - Curso de Engenharia Química, Programa de Pós-graduação em Engenharia Química, Universidade Federal do Rio Grande do Norte, Natal, 2000.

BORRELY, S. I. et al. Decoloration and detoxification of effluents by ionizing radiation. Radiation Physics and Chemistry, [S.l.], p. 1-5, 2015.

BOUAOUINE, O. et al. Comparative study between Moroccan cactus and chemicals coagulants for textile effluent treatment. Journal of Materials and Environmental Science, [S.I.], v. 8, p. 26872693, 2017.

BRASIL. Decreto-Lei n. 9.605, de 12 de fevereiro de 1998. Dispõe sobre as sanções penais e administrativas derivadas de condutas e atividades lesivas ao meio ambiente, e dá outras providências. Brasília, DF, 1998. Disponível em: http://www.planalto.gov.br/ccivil_03/leis/L9605.htm. Acesso em: 12 set. 2019.

BRASIL. Resolução n. 430, de 13 de maio de 2011. Dispõe sobre as condições e padrões de lançamento de efluentes, complementa e altera a Resolução n. 357, de 17 de março de 2005, do Conselho Nacional do Meio Ambiente-CONAMA. Diário Oficial da União, 2011. Disponível em: http://www2.mma.gov.br/port/conama/legiabre.cfm?codlegi=646. Acesso em: 12 set. 2019.

CAMPOS, V. M.; BRITO, N. N. Tratamento de efluente têxtil utilizando coagulação/floculação e Fenton. Revista de Química Industrial, [S.l.], v. 82, n. 743, p. 11-17, 2014.

COSTA, A. F. S. et al. Color removal from industrial dyeing and laundry effluent by microbial consortium and coagulant agents. Process Safety and Environmental Protection, [S.l.], v. 118, p. 203-210, 2018.

FANG, Y. X. et al. Use of TIE techniques to characterize industrial effluents in the Pearl River Delta region. Ecotoxicology and Environmental Safety, [S.l.], v. 76, n.1, p. 143-152, 2012.

FERNANDES, T. F. et al. Estudo e Monitoramento Tecnológico do Tratamento de Efluentes por Eletrocoagulação. Caderno de Prospecção, Salvador, v. 12, n. 2, p. 388, 2019. 
FREITAS, T. K. F. S. et al. Optimization of coagulation-flocculation process for treatment of industrial textile wastewater using okra (A. esculentus) mucilage as natural coagulant. Industrial Crops and Products, [S.l.], v. 76, p. 538-544, 2015.

FURLAN, F. R. Avaliação da eficiência do processo de coagulação-floculação e adsorção no tratamento de efluentes têxteis. 2008. 151 p. Dissertação (Mestrado) - Programa de PósGraduação em Engenharia Química. Centro Tecnológico da Universidade Federal de Santa Catarina, Florianópolis, 2008. Disponível em: http://repositorio.ufsc.br/xmlui/handle/123456789/91020. Acesso em: 8 set. 2019.

LIMA JÚNIOR, R. N.; ABREU, F. O. M. S. Produtos Naturais Utilizados como Coagulantes e Floculantes para Tratamento de Águas: Uma Revisão sobre Benefícios e Potencialidades. Revista Virtual de Química, [S.I.], v. 10, n. 3, p. 709-735, 2018.

LUNA, L. A. V. et al. Aquatic toxicity of dyes before and after photo-Fenton treatment. Journal of Hazardous Materials, [S.l.], v. 276, n. 2014, p. 332-338, 2014.

LOPES, E. C. et al. Evaluation of a tannin-based coagulant on the decolorization of synthetic effluents. Journal of Environmental Chemical Engineering, [S.I.], v. 7, n. 3, p. 103-125, 2019.

LOZANO-RIVAS, W. A. et al. Use of glycosides extracted from the fique (Furcraea sp.) in wastewater treatment for textile industry. International Journal of Environmental Science and Technology, [S.l.], v. 13, n. 4, p. 1.131-1.136, 2016.

KUNZ, A.; REGINATTO, V.; DÚRAN, N. Combined treatment of textile effluent using the sequence Phanerochaete chrysosporium-ozone. Chemosphere, [S.l.], v. 44, n. 2, p 281-287, 2001.

MAGNAN, R. B. Análise da viabilidade técnica e financeira da substituição do coagulante cloreto férrico por policloreto de alumínio durante o processo físico-químico no tratamento de efluente de abatedouro avícola. 2010. 54 p. Trabalho de Conclusão de Curso (Graduação) - Faculdade de Engenharia e Arquitetura, Universidade de Passo Fundo, Passo Fundo, 2010. Disponível em: http://usuarios.upf.br/ engeamb/TCCs/2010-2/RAFAEL\%20MAGNAN.pdf. Acesso em: 14 set. 2019.

MAHMOUED, E. K. Cement kiln dust and coal filters treatment of textile industrial effluents. Desalination, [S.I.], v. 255, n. 1-3, p. 175-178, 2010.

MARTINS, H. C. Estudo sobre os processos de coagulação, floculação e decantação em efluentes oriundos de usina canavieira. 2014. 56 p. Trabalho de Conclusão de Curso. Curso Superior de Engenharia Ambiental. Universidade Tecnológica Federal do Paraná, Londrina, 2014. Disponível em: http://repositorio.roca.utfpr.edu.br/jspui/bitstream/1/2668/1/LD_COEAM_2013_2_10. pdf. Acesso em: 6 nov. 2019.

MORAIS, N. W. S.; SANTOS, A. B. Análise dos padrões de lançamento de efluentes em corpos hídricos e de reuso de águas residuárias de diversos estados do Brasil. Revista do Departamento de Águas e Esgotos - DAE, [S.l.], v. 67, p. 40-55, n. 215, 2019.

MURALIMOHAN, N.; PALANISAMY, T.; VIMALADEVI, M. N. Experimental study on removal efficiency of blended coagulants in textile wastewater treatment. IMPACT: International Journal of Research in Engineering \& Technology, [S.l.], v. 2, n. 2, p. 15-20, 2014.

MURALIMOHAN, N.; PALANYSAMY, T. Treatment of textile effluent by natural coagulants in Erode district. Asian Journal of Chemistry, [S.l.], v. 26, n. 3, p. 911-914, 2014. 
PAGAN, E. V. Reuso da água industrial: Estudos de caso em indústrias têxteis.2011. $54 \mathrm{f}$. Monografia (Especialização) - Curso de Engenharia Química, Departamento de Engenharia Química, Universidade Federal do Ceará, Fortaleza, 2011. Disponível em: http://www.eq.ufc.br/TFC/ TFC_2011_Pagan.pdf. Acesso em: 25 ago. 2019.

PALEARI, T. H. Coagulantes naturais e coagulante químico para o tratamento de efluente de indústria de café solúvel. 2014. 118 p. Projeto de Pesquisa - Coordenação do Curso de Engenharia Ambiental, Universidade Tecnológica Federal do Paraná, Londrina, 2014. Disponível em: http://repositorio.roca.utfpr.edu.br/jspui/bitstream/1/5201/1/LD_COEAM_2014_2_20.pdf. Acesso em: 14 set. 2019.

PATEL, H.; VASHI, R. T. Comparison of naturally prepared coagulants for removal of COD and color from textile wastewater. Global NEST Journal, [S.l.], v. 15, n. 4, p. 522-528, 2013.

PAVANKUMAR, A. R.; SINGH, L. Identification of Moringa oleifera protein responsible for the decolorization and pesticide removal from drinking water and industrial effluent-an in silico and in situ evaluation. Journal of Chemical Technology \& Biotechnology, [S.l.], v. 90, n. 8, p. 15211526, 2015.

QUEIROZ, M. T. A. et al. Gestão de resíduos na indústria têxtil e sua relação com a qualidade da água: estudo de caso. Ibero american Journal of Industrial Engineering, [S.I.], v. 8, n. 15, p. 114-135, 2016.

RESENDE, L. P. Reuso na indústria têxtil e lavanderias. Revista Hydro, [S.l.], v. 6, p. 14-19, 2012.

RIO GRANDE DO SUL (Estado). Resolução n. 128, de 24 de novembro de 2006, do Conselho Estadual Do Meio Ambiente - CONSEMA. Dispõe sobre a fixação de Padrões de Emissão de Efluentes Líquidos para fontes de emissão que lancem seus efluentes em águas superficiais no Estado do Rio Grande do Sul. Diário Oficial da República Federativa do Brasil, Brasília, DF, 24 de novembro de 2006. Disponível em: https://www.sema.rs.gov.br/upload/ arquivos/201611/30155644-resolucao-128-06-efluentes.pdf. Acesso em: 12 set. 2019.

SALEEM, M.; BACHMANN, R. T. A contemporary review on plant-based coagulants for applications in water treatment. Journal of Industrial and Engineering Chemistry, [S.I.], v. 72, p. 281-297, 2019.

SAMUEL, O. B.; OSUALA, F. I.; ODEIGAH, P. G. C. Cytogeno toxicity evaluation of two industrial effluents using Allium cepa assay. African Journal of Environmental Science and Technology, [S.l.], v. 41, n. 1, p. 21-27, 2010.

SANTOS, B. S. et al. Continuous electrochemical reactor improved by the addition of Moringa oleifera lam extract: optimization of operational conditions for Blue $5 G$ dye removal. Revista Ambiente \& Água, [S.1.], v. 14, n. 3, 2019.

SANTOS, G. O. F. Avaliação do Tratamento de Efluentes do banho de tingimento de indústria têxtil por fungos basidiomicetos em biorreatores. 2016. 175p. Tese (Doutorado) - Programa de Pós-Graduação Interunidades em Biotecnologia, Instituto Butantan, Instituto de Pesquisas Tecnológicas, Universidade de São Paulo, São Paulo, 2016. Disponível em: http://www.teses.usp.br/ teses/disponiveis/87/87131/tde-26082016-10013x0/pt-br.php. Acesso em: 14 set. 2019.

SANTOS, J. D. et al. Use of different coagulants for cassava processing wastewater treatment. Journal of Environmental Chemical Engineering, [S.I.], v. 6, n. 2, p. 1821-1827, 2018. 
SCHOENHALS, M.; PORTO, A. E. Tratamento de efluentes, reuso de água e legislação aplicada em lavanderia têxtil industrial. III Simpósio Ambiental da Universidade Tecnológica Federal do Paraná, [S.l.], v. 10, n. 2, p. 28-30, 2012.

SHAMSNEJATI, S. et al. Mucilaginous seed of Ocimum basilicum as a natural coagulant for textile wastewater treatment. Industrial Crops and Products, [S.l.], v. 69, p. 40-47, 2015.

SILVA, S. C. Tratamento Químico e Biológico de efluentes da Indústria Têxtil como forma de redução do impacto ambiental aos recursos hídricos - Estudo de caso: Mar indústria Têxtil e Tinturaria Ltda. Monografia (Especialização) - Curso de Auditoria e Perícia Ambiental, Curso de Pós-graduação Especialização em Auditoria e Perícia Ambiental, Universidade do Extremo Sul Catarinense, Criciúma, 2011. Disponível em: http://repositorio.unesc.net/bitstream/1/1029/1/ Simone\%20Cust\%C3\%B3dio\%20Da\%20Silva.pdf. Acesso em: 26 ago. 2019.

SOUZA, M. T. F. et al. The use of a natural coagulant (Opuntia ficus-indica) in the removal for organic materials of textile effluents. Environmental Monitoring and Assessment, [S.l.], v. 186, n. 8, p. 5.261-5.271, 2014.

SOUZA, M. T. F. et al. Extraction and use of Cereus peruvianus cactus mucilage in the treatment of textile effluents. Journal of the Taiwan Institute of Chemical Engineers, [S.I.], v. 67, p. 174-183, 2016.

TWARDOKUS, R. G. Reuso de água no processo de tingimento da indústria têxtil. 2004. 136

f. Dissertação (Mestrado) - Curso de Engenharia Química, Centro Tecnológico da Universidade Federal de Santa Catarina, Universidade Federal de Santa Catarina, Florianópolis, 2004.

VILASECA, M.; LÓPEZ-GRIMAU, V.; GUTIÉRREZ-BOUZÁN, C. Valorization of waste obtained from oil extraction in Moringa oleifera seeds: coagulation of reactive dyes in textile effluents. Materials, [S.l.], v. 7, n. 9, p. 6.569-6.584, 2014.

\section{Sobre os Autores}

\section{Jéssica Gabryelle dos Santos Silva}

E-mail: jessicagabryele@hotmail.com

Bacharel em Engenharia Química pela Universidade Salvador (UNIFACS) em 2019.

Endereço profissional: Rua Leonardo Galvão, n. 19, Centro, Campo Formoso, BA. CEP: 44790-000.

\section{Renato Souza Mendes Junior}

E-mail: renato1mendesjr@gmail.com

Bacharel em Engenharia Química pela Universidade Salvador (UNIFACS) em 2019.

Endereço profissional: Avenida Cardeal da Silva, n. 1.729, Federação, Salvador, BA. CEP: 40231-305.

\section{Ana Katerine de Carvalho Lima Lobato}

E-mail: ana.lobato@unifacs.br

Doutorado em Engenharia Química pela Universidade Federal do Rio Grande do Norte (UFRN) em 2010.

Endereço profissional: Av. Juracy Magalhães Júnior, n. 209, Rio Vermelho, Salvador, BA. CEP: 41940-060. 